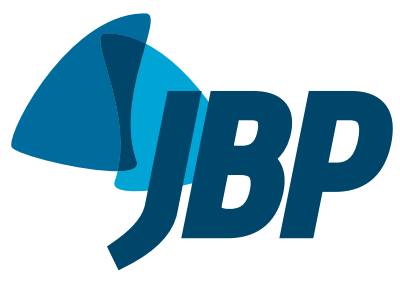

\title{
State-dependent changes in the upper airway assessed by multidetector CT in healthy individuals and during obstructive events in patients with sleep apnea
}

\author{
Ula Lindoso Passos ${ }^{1, a}$, Pedro Rodrigues Genta, ${ }^{1, b}$, Bianca Fernandes Marcondes ${ }^{2, c}$, \\ Geraldo Lorenzi-Filho ${ }^{2, d}$, Eloisa Maria Mello Santiago Gebrim ${ }^{1, e}$
}

1. Hospital das Clínicas, Faculdade de Medicina, Universidade de São Paulo, São Paulo (SP) Brasil.

2. Faculdade de Medicina, Universidade de São Paulo, São Paulo (SP) Brasil.

a. (iD) http://orcid.org/0000-0002-0789-1681

b. (D) http://orcid.org/0000-0002-6764-165X

c. iD http://orcid.org/0000-0002-3190-8797

d. (D) http://orcid.org/0000-0002-7011-7373

e. (D) http://orcid.org/0000-0002-6514-3825

Submitted: 21 September 2018.

Accepted: 23 February 2019

Study carried out at the Hospital das Clínicas, Faculdade de Medicina,

Universidade de São Paulo,

São Paulo (SP) Brasil.

\begin{abstract}
Objective: To determine whether airway narrowing during obstructive events occurs predominantly at the retropalatal level and results from dynamic changes in the lateral pharyngeal walls and in tongue position. Methods: We evaluated 11 patients with severe obstructive sleep apnea (OSA) and 7 healthy controls without OSA during wakefulness and during natural sleep (documented by full polysomnography). Using fast multidetector CT, we obtained images of the upper airway in the waking and sleep states. Results: Upper airway narrowing during sleep was significantly greater at the retropalatal level than at the retroglossal level in the OSA group $(p<0.001)$ and in the control group $(p<$ 0.05). The retropalatal airway volume was smaller in the OSA group than in the control group during wakefulness $(p<0.05)$ and decreased significantly from wakefulness to sleep only among the OSA group subjects. Retropalatal pharyngeal narrowing was attributed to reductions in the anteroposterior diameter $(p=0.001)$ and lateral diameter $(p=0.006)$, which correlated with an increase in lateral pharyngeal wall volume $(p=$ $0.001)$ and posterior displacement of the tongue $(p=0.001)$, respectively. Retroglossal pharyngeal narrowing during sleep did not occur in the OSA group subjects. Conclusions: In patients with OSA, upper airway narrowing during sleep occurs predominantly at the retropalatal level, affecting the anteroposterior and lateral dimensions, being associated with lateral pharyngeal wall enlargement and posterior tongue displacement.

Keywords: Multidetector computed tomography; Oropharynx; Sleep apnea, obstructive; Polysomnography; Diagnostic imaging; Sleep.
\end{abstract}

\section{INTRODUCTION}

Obstructive sleep apnea (OSA) is characterized by repetitive partial or complete upper airway obstruction during sleep. OSA is common in the general population and can have many consequences, including fragmented sleep, excessive daytime sleepiness, poor quality of life, and poor cardiovascular outcomes. ${ }^{(1-3)}$ The main pathophysiological mechanism in OSA involves changes in the configuration of the upper airway anatomy. The upper airway remains patent during wakefulness but collapses during sleep, when the upper airway muscles relax.(4) Studies using standard imaging modalities, such as $\mathrm{X}$-ray, ${ }^{(5-7)} \mathrm{CT}^{(8-11)}$ and magnetic resonance imaging $(M R I),{ }^{(12-16)}$ to examine the upper airway in patients with OSA have shown that bone and soft tissue characteristics can both increase the risk of OSA. The major risk factor for OSA is obesity, which has been associated with enlargement of the pharyngeal soft tissues, especially the tongue. ${ }^{(11,13)}$ However, the state-dependent behavior of the tongue, soft palate, and lateral walls that leads to upper airway obstruction in patients with OSA is poorly understood.

Pharyngeal obstruction can be visualized directly through drug-induced sleep endoscopy (DISE). ${ }^{(17)}$ However, DISE has some technical limitations: it is invasive and does not allow precise measurements, because of image distortion and the lack of clear anatomical landmarks. More importantly, observation of the pharyngeal lumen during endoscopy provides no insights regarding the surrounding structures. Similarly, MRI of the upper airway during sleep provides limited information because of the technical difficulties involved in monitoring patients and acquiring images during sleep. ${ }^{(18-21)}$ Multidetector CT uses relatively low doses of radiation, allows fast acquisition, and produces high quality three-dimensional (3D) reconstructions of the upper airway. A limited number of studies, involving small samples of subjects, have used CT and MRI to examine the upper airway during sleep.(20-24) Such studies have suggested that the primary site of upper airway obstruction is in the retropalatal region. An even smaller number of studies have characterized the state-dependent pattern of airway collapse. ${ }^{(18,20,24)}$

The primary purpose of the present study was to document the state-dependent behavior of the structures surrounding the pharynx during upper airway obstruction, using multidetector $\mathrm{CT}$, during well-documented natural sleep in patients with OSA and healthy controls. We hypothesized that airway narrowing occurs predominantly

Correspondence to:

Ula Lindoso Passos. Rua Embuaçu, 179, apto. 242, 24 andar, CEP 04118-080, São Paulo, SP, Brasil.

Tel.: 5511 98181-2199. Fax: 5511 5084-2034. E-mail: ulapassos@gmail.com

Financial support: None. 
in the retropalatal region and results from dynamic changes in the lateral pharyngeal walls and tongue position.

\section{METHODS}

\section{Subjects}

Male patients with a recent diagnosis of severe OSA, defined as an apnea-hypopnea index $(\mathrm{AHI}) \geq 30$ events/h, were recruited for the study. Patients with a body mass index (BMI) $\geq 35 \mathrm{~kg} / \mathrm{m}^{2}$ were excluded, as were those with congestive heart failure, neuromuscular disease, coronary artery disease, or a history of stroke. As a control group, healthy male subjects were recruited from among the hospital staff. From the control group, we excluded subjects who reported snoring, subjects who were using any medication, and subjects with an AHI > 5 events/h (Table 1 ). The local research ethics committee approved the study, and all participants gave written informed consent.

\section{Sleep evaluation}

All of the patients in the OSA group were evaluated by full polysomnography on a digital system (EMBLA; Flaga Medical Devices, Reykjavík, Iceland) with the following parameters $^{(25)}$ : electroencephalography (electrodes C3/ $A 2, C 4 / A 1,01 / A 2$, and O2/A1); electrooculography; electromyography of the submental and anterior tibialis muscles; snoring, identified with a snoring sensor; air flow, as measured with oronasal thermistor and nasal pressure cannula; chest and abdominal wall movements, identified with thoracic and abdominal belts, respectively; electrocardiography; sleep position, determined with a body position detector; oxygen saturation; and heart rate. Among the healthy (control group) subjects, the absence of OSA was confirmed with a type III portable home monitor, which assessed nasal flow (with a nasal pressure cannula), thoracic/ abdominal movement, pulse oximetry, and body position (Stardust; Philips Respironics, Murrysville, PA, USA). All sleep studies were scored manually by the same experienced technician, who was blinded to the clinical status of the subjects. An episode of apnea was defined as $a \geq 90 \%$ reduction in flow amplitude for at least $10 \mathrm{~s}$. An episode of hypopnea was defined as a $\geq 50 \%$ reduction in flow amplitude, accompanied by $\geq 3 \%$ oxygen desaturation or $\mathrm{a} \geq 10 \mathrm{~s}$ awakening. ${ }^{(26)}$

\section{Study design}

Subjects were instructed to restrict their sleep to less than $4 \mathrm{~h}$ on the night previous to the CT study and to arrive at the radiology department in the early afternoon after a light meal, having consumed no caffeinated beverages or alcohol on the day of the study, and wearing comfortable clothes. During the CT scans, all subjects were monitored with the same equipment and electrodes used in the full polysomnography, with the exception of the submental and anterior tibialis muscle electromyography electrodes, which were not employed. The polysomnography signals were continuously displayed in the CT control room on a dedicated laptop computer. The CT scanning table was outfitted with a customized mattress and arm supports. Images of the upper airway were initially obtained during wakefulness. The subjects were then instructed to close their eyes and relax. The lights were then turned off. The second series of CT images was acquired after at least 2 min of stable (stage 1 or 2) sleep, during stable breathing in controls and during respiratory events in patients with OSA. A time stamp was issued to the polysomnography acquisition system when the CT scanner was triggered.

\section{CT imaging}

The upper airway was imaged in a 16-slice multidetector CT scanner (IDT 16; Philips Medical Systems, Best, The Netherlands). During the CT study, subjects were placed in the supine position, their head being fixed to the scanner head rest with adhesive tape. Images were acquired from the level of the hard palate to the level of the hypopharynx. The following parameters were used: collimation, 1.5 $\mathrm{mm}$; interslice gap, $1 \mathrm{~mm}$; voltage, $120 \mathrm{kV}$; current, $140 \mathrm{mAs}$; and rotation time, $1 \mathrm{~s}$.

\section{Anatomical measurements}

Axial and sagittal 3D reconstructions were performed to allow linear measurements using an Extended Brilliance Workspace (Philips Medical Systems). As previously described, ${ }^{(18,27)}$ the retropalatal region was defined as that ranging from the hard palate to the tip of the uvula, and the retroglossal region was defined as that ranging from the tip of the uvula to one slice above the epiglottis. Sagittal reconstructions were used in order to measure the length and width of the soft palate, as well as to determine the distance from the edge of

Table 1. Demographic characteristics of the study participants. ${ }^{a}$

\begin{tabular}{lcc}
\multicolumn{1}{c}{ Characteristic } & Group & OSA \\
& Control & (n $=11$ ) \\
Age, years & $(\mathbf{n}=7)$ & $57.7 \pm 14.6$ \\
BMl, kg/m ${ }^{2}$ & $30.3 \pm 4.2$ & $34.5 \pm 5.7$ \\
Neck circumference, cm & $27.7 \pm 2.6$ & $45.6 \pm 4.2$ \\
AHI, events/h & $42 \pm 1.7$ & $57.1 \pm 19.5$ \\
Lowest oxygen saturation, \% & $2.2 \pm 1.2$ & $67 \pm 10.6$ \\
\hline
\end{tabular}

OSA: obstructive sleep apnea; BMI: body mass index; and AHI: apnea-hypopnea index. ${ }^{\text {Results expressed as }}$ mean $\pm S D$ 
the posterior third of the oral tongue and the posterior pharyngeal wall, designated the tongue-pharyngeal distance and measured at the level of the superior border of the $\mathrm{C} 2$ vertebral body (Figures 1 and 2). The limits of the lateral pharyngeal walls and tongue were defined by manually tracing their contours on each axial image (Figure 1). Volumetric reconstructions of the lateral pharyngeal walls and tongue were performed. Tongue volume was not determined during sleep, because airway narrowing, together with apposition between the soft palate and the tongue, precluded definition of the borders between the soft palate and the tongue. The lateral pharyngeal walls are delimited medially by air and laterally by the parapharyngeal space, which has a lower attenuation due to fat. The anterior border is defined by the anterior contour of the palatine tonsil and follows a diagonal line parallel to the anterior border of medial pterygoid muscle in a caudal direction towards the glossotonsillar sulcus. The upper landmark is the hard palate, and the lower landmark is the tip of the free margin of the epiglottis (Figures 1 and 2). Linear and area measurements were obtained at the narrowest point of the upper airway, at the retropalatal and retroglossal levels (Figure 1 ). Upper airway volume was quantified through the use of a segmentation technique based on a fixed threshold characteristic of air ( $-1024 \mathrm{HU}$ to $-800 \mathrm{HU})$ and was assessed for the retropalatal and retroglossal regions. To determine the level of intraobserver agreement, lateral pharyngeal wall volume was measured twice in each of 5 OSA group subjects.

\section{Statistical analysis}

Data were analyzed using the Statistical Analysis System, version 9.2 (SAS Institute Inc., Cary, NC, USA). Continuous variables are expressed as means and standard deviations or as medians and interquartile ranges. A general linear model for repeated measures was used in order to compare upper airway measurements among patients and controls during wakefulness and during sleep. Pearson's correlation coefficient was used in order to determine whether the state-dependent changes in the tongue-pharyngeal distance were associated with the dimensions of the retropalatal region and lateral pharyngeal wall. $A$ paired t-test was used in order to compare the

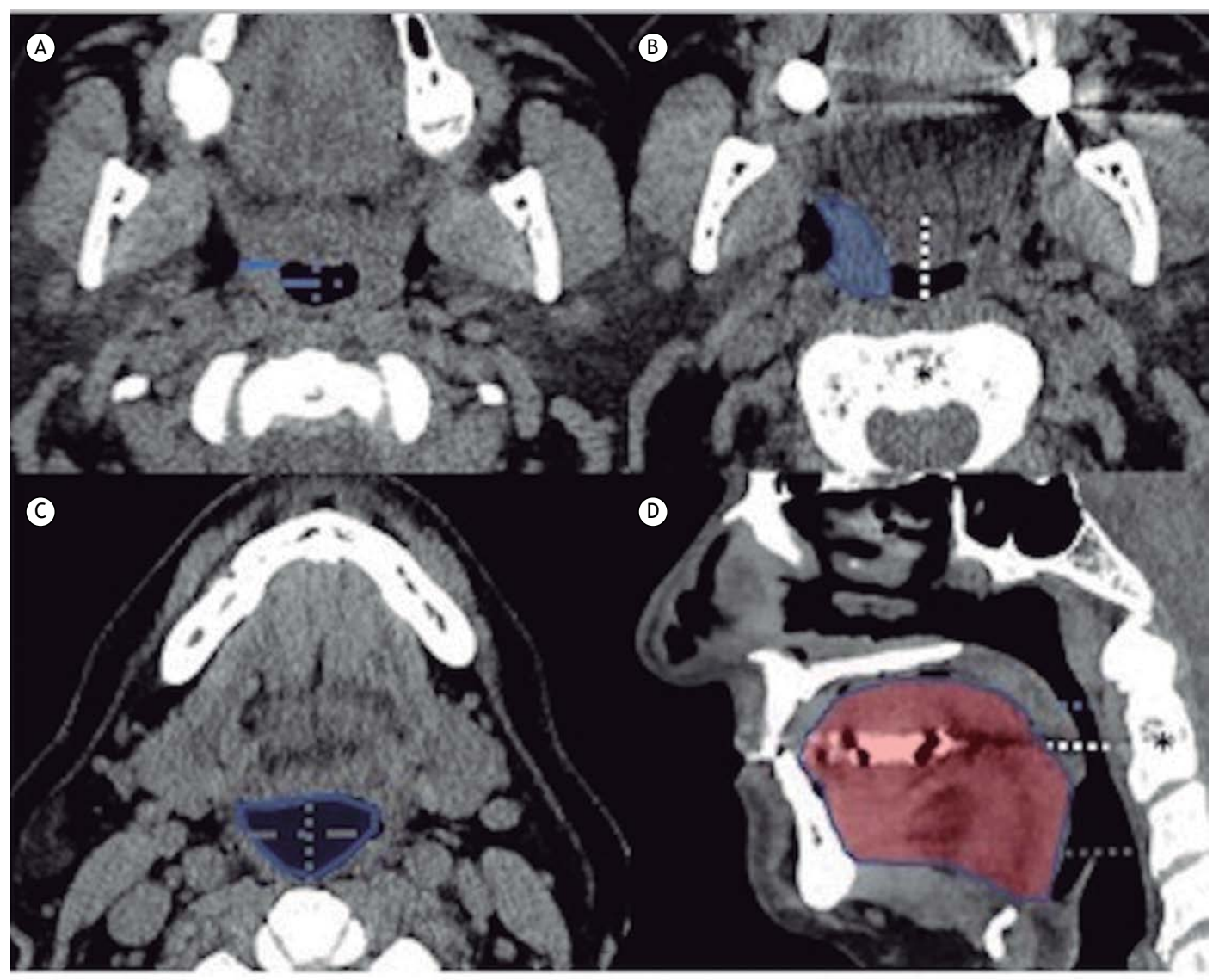

Figure 1. Representative axial and sagittal CT reconstructions of the pharynx during wakefulness in a patient with obstructive sleep apnea. Retropalatal region (A), at the level of the superior border of the C2 vertebral body (* in B), and retroglossal region $(C)$. Contour of the lateral wall (blue outline in $B$ ) and lateral wall thickness (solid line in $A$ ); anteroposterior diameter of the pharynx (dotted lines in A, C, and D) and lateral diameter of the pharynx (dashed line in $A$ and $C$ ); tongue-pharyngeal distance (white dotted line in $D$ ); retroglossal area (solid contour in $C$ ) and tongue delimitation (red area in D). 

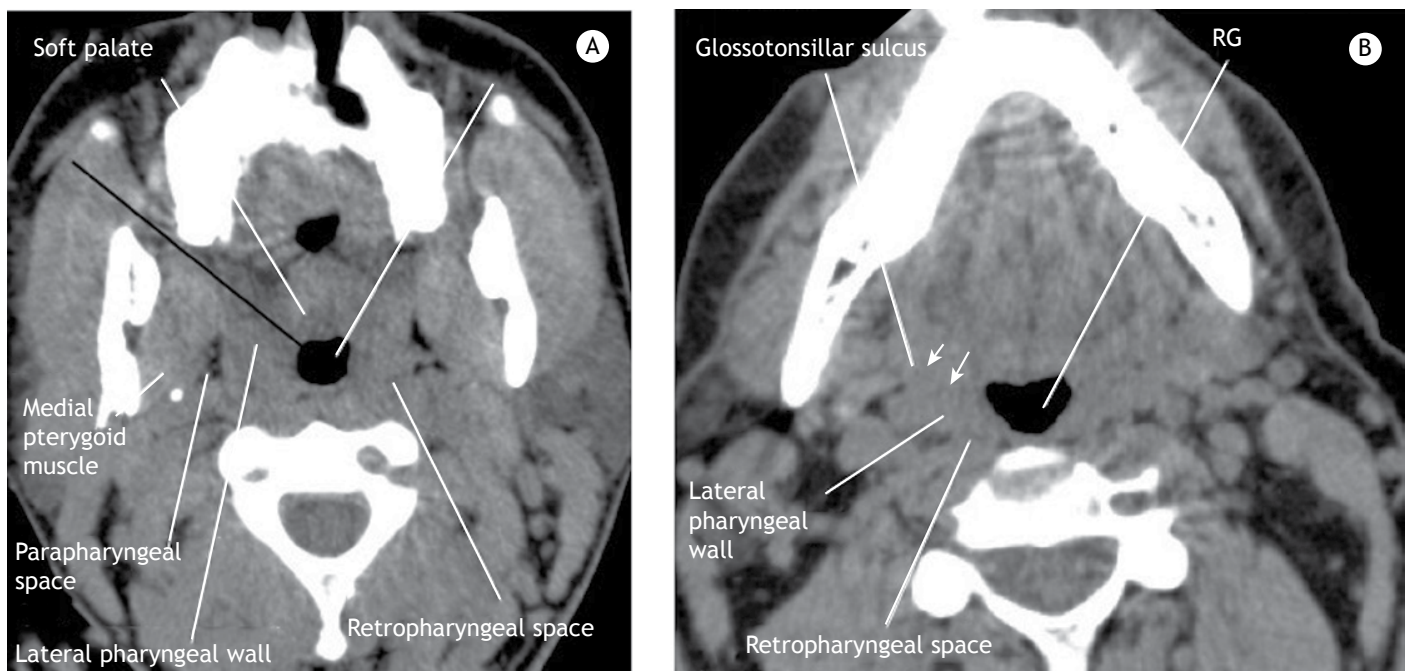

Figure 2. Axial CT images of the retropalatal (RP) and retroglossal (RG) regions ( $A$ and $B$, respectively). The lateral pharyngeal walls are delimited medially by air. The black line in A represents the anterior aspect of the medial border of the lateral pharyngeal wall. The glossotonsillar sulcus (arrows) marks the anterior limit of the lateral pharyngeal wall at the RG level (B). The lateral pharyngeal wall is delimited laterally by the parapharyngeal space and posteriorly by the retropharyngeal space.

waking and sleep states in terms of the retropalatal and retroglossal airway volumes. An unpaired t-test was used in order to compare the patients who were included in the study with those who were excluded. Using a two-way mixed-effects model, we calculated intraclass correlation coefficients in order to determine the level of intraobserver agreement for lateral wall volume measurements. Values of $p \leq 0.05$ were considered statistically significant.

\section{RESULTS}

A total of 29 male subjects were enrolled in this study (11 healthy controls and 18 patients with OSA). A total of 11 subjects (4 control group subjects and 7 OSA group subjects) failed to fall asleep during the CT examination and were excluded. Therefore, the final sample comprised 18 subjects ( 7 in the control group and 11 in the OSA group). During wakefulness, no significant differences were observed between the patients with OSA who were included and those who were excluded in terms of the $C T$ variables evaluated. However, there were differences between the control and OSA groups in terms of the mean values for age ( $58 \pm 15$ years vs. $30 \pm 4$ years), BMI ( $34 \pm 6 \mathrm{~kg} / \mathrm{m}^{2}$ vs. $\left.28 \pm 3 \mathrm{~kg} / \mathrm{m}^{2}\right)$, AHI $(2 \pm 1$ events $/ \mathrm{h}$ vs. $57 \pm 19$ events/h), and lowest oxygen saturation ( $67 \pm 10 \%$ vs. $89 \pm 2 \%$ ), all of which were statistically significant $(p<0.05$ for all).

The duration of each CT acquisition was 4-6 s. The time from CT acquisition during wakefulness to $C T$ acquisition during sleep was 5-90 min. All sleep-state CT scans were acquired during stable breathing in the control group subjects and during obstructive respiratory events, characterized by episodes of hypopnea $(n=4)$ or apnea $(n=7)$, in the OSA group subjects.
Representative examples of 3D reconstructions of the upper airway and lateral pharyngeal walls during wakefulness and sleep in a control group subject and in an OSA group subject are shown in Figure 3. The mean tongue volume during wakefulness was significantly greater in the OSA group than in the control group $\left(14.9 \pm 2.4 \mathrm{~cm}^{3}\right.$ vs. $\left.11.4 \pm 1.1 \mathrm{~cm}^{3} ; \mathrm{p}<0.001\right)$.

Linear and volumetric measurements of the upper airway in the waking and sleep states, in the control and OSA groups, are shown in Table 2 . In both groups, upper airway narrowing from wakefulness to sleep was more pronounced at the retropalatal level than at the retroglossal level. In addition, the mean change in airway volume from wakefulness to sleep differed significantly between the retropalatal and retroglossal regions in the OSA group $(-45.0 \pm 21.3 \%$ vs. $16.9 \pm 38.5 \%$; $p<0.001)$ and in the control group $(-10.8 \pm 17.1 \%$ vs. $3.0 \pm 12.3 \% ; p=0.016$ ). As can also be seen in Table 2, there were trends toward state-dependent reductions (from wakefulness to sleep) in the mean dimensions of the retropalatal region in the control group: anteroposterior diameter $(\mathrm{p}=0.118)$; lateral diameter $(p=0.120)$; and airway volume $(p=0.129)$.

In the OSA group, the cross-sectional area of the retropalatal airway decreased from $0.73 \pm 0.40 \mathrm{~cm}^{2}$ in the waking state to $0.19 \pm 0.17 \mathrm{~cm}^{2}$ in the sleep state $(p<0.001)$. Also within the retropalatal airway (Table 2), the OSA group subjects showed similar state-dependent reductions (from wakefulness to sleep) in the mean anteroposterior diameter ( 0.71 $\pm 0.25 \mathrm{~cm}$ to $0.46 \pm 0.28 \mathrm{~cm} ; \mathrm{p}<0.001)$ and mean lateral diameter $(1.18 \pm 0.49 \mathrm{~cm}$ to $0.74 \pm 0.54 \mathrm{~cm}$; $\mathrm{p}=0.006$ ). As can be seen in Figure 4 , there was also a reduction in the mean retropalatal airway volume in the OSA group, in which it decreased from $2.64 \pm$ $1.00 \mathrm{~cm}^{3}$ during wakefulness to $1.39 \pm 0.72 \mathrm{~cm}^{3}$ during 


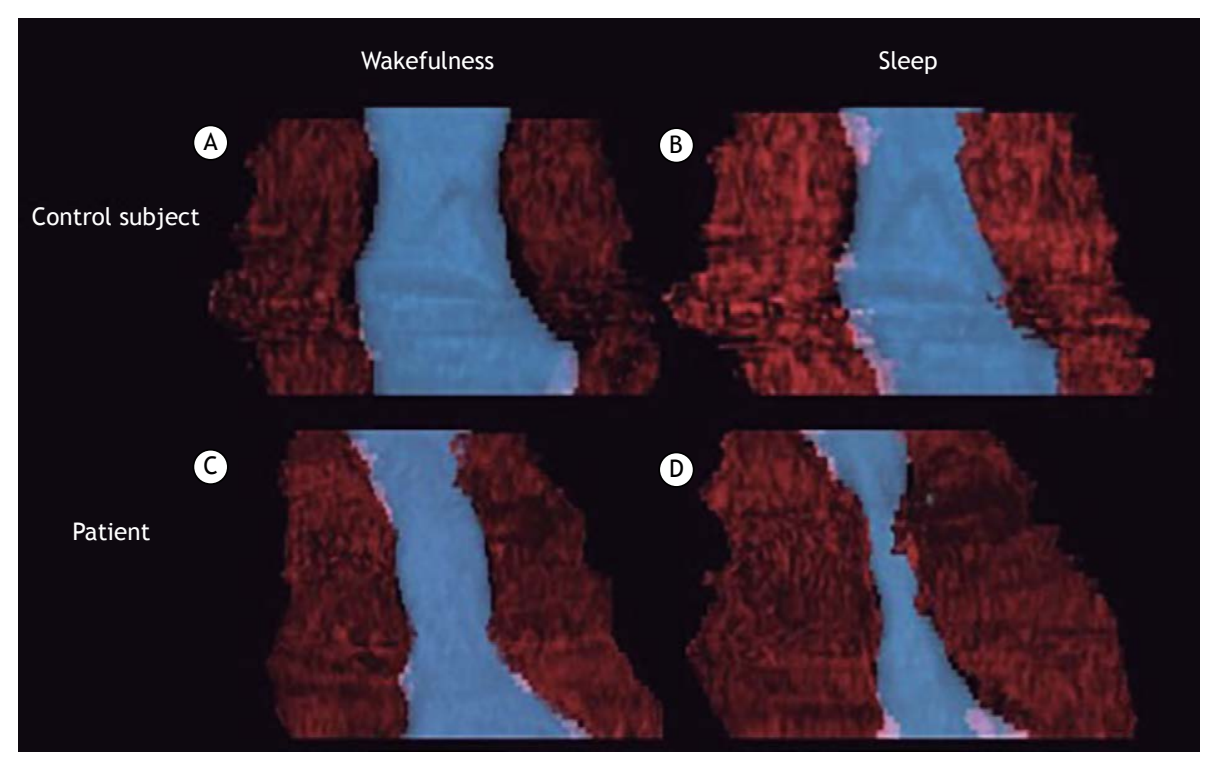

Figure 3. Three-dimensional reconstructions of the upper airway of a representative control subject (A and $B)$ and of a patient with obstructive sleep apnea (OSA; $C$ and $D$ ). The lateral pharyngeal walls (in red) and the airway lumen (in blue) during wakefulness ( $A$ and $C$ ) and sleep ( $B$ and $D$ ). From wakefulness to sleep, the lateral walls and airway lumen remained unchanged in the control subject, whereas there was widening of the lateral pharyngeal walls and narrowing of the airway lumen in the patient with OSA.

Table 2. Linear and volumetric measurements of soft tissue and airway spaces in waking and sleep states.

\begin{tabular}{|c|c|c|c|c|c|c|c|}
\hline \multirow[t]{3}{*}{ Parameter } & \multicolumn{6}{|c|}{ Group } & \multirow[t]{3}{*}{$\mathbf{p}^{\dagger}$} \\
\hline & \multicolumn{3}{|c|}{$\begin{array}{l}\text { Control } \\
(n=7)\end{array}$} & \multicolumn{3}{|c|}{$\begin{array}{c}\text { OSA } \\
(n=11)\end{array}$} & \\
\hline & Waking & Sleep & p* & Waking & Sleep & p* & \\
\hline \multicolumn{8}{|l|}{ Retropalatal space } \\
\hline Anteroposterior diameter, $\mathrm{cm}$ & $0.76 \pm 0.14$ & $0.81 \pm 0.20$ & 0.118 & $0.71 \pm 0.25$ & $0.46 \pm 0.28$ & 0.001 & 0.001 \\
\hline Lateral diameter, $\mathrm{cm}$ & $1.76 \pm 0.30$ & $1.31 \pm 0.65$ & 0.128 & $1.18 \pm 0.49$ & $0.74 \pm 0.54$ & 0.006 & 0.398 \\
\hline Area, $\mathrm{cm}^{2}$ & $1.18 \pm 0.25$ & $1.08 \pm 0.43$ & 0.399 & $0.73 \pm 0.40$ & $0.19 \pm 0.17$ & 0.001 & 0.001 \\
\hline Lateral wall thickness, $\mathrm{cm}$ & $1.24 \pm 0.31$ & $1.28 \pm 0.26$ & 0.534 & $1.53 \pm 0.38$ & $1.67 \pm 0.41$ & 0.193 & 0.890 \\
\hline Lateral wall volume, $\mathrm{cm}^{3}$ & $11.5 \pm 3.1$ & $11.3 \pm 3.2$ & 0.878 & $15.8 \pm 6.3$ & $20.1 \pm 8.9$ & 0.001 & 0.010 \\
\hline Soft palate thickness, $\mathrm{cm}$ & $0.91 \pm 0.20$ & $0.91 \pm 0.20$ & 1 & $1.20 \pm 0.25$ & $1.10 \pm 0.21$ & 0.340 & 0.443 \\
\hline Soft palate length, cm & $3.39 \pm 0.27$ & $3.36 \pm 0.26$ & 0.356 & $4.40 \pm 0.69$ & $4.50 \pm 0.56$ & 0.341 & 0.484 \\
\hline TP distance, $\mathrm{cm}$ & $1.58 \pm 0.41$ & $1.56 \pm 0.47$ & 0.898 & $1.89 \pm 0.28$ & $1.62 \pm 0.32$ & 0.001 & 0.035 \\
\hline Fat pad volume, $\mathrm{cm}^{3}$ & $1.60 \pm 0.87$ & $1.65 \pm 0.81$ & 0.916 & $3.15 \pm 2.30$ & $2.08 \pm 1.74$ & 0.006 & 0.900 \\
\hline Airway volume, $\mathrm{cm}^{3}$ & $3.19 \pm 0.97$ & $2.82 \pm 0.94$ & 0.129 & $2.64 \pm 1.00$ & $1.39 \pm 0.72$ & 0.001 & 0.003 \\
\hline Tongue volume, $\mathrm{cm}^{3}$ & $11.4 \pm 1.10$ & $-\cdot-\cdot$ & --.- & $14.9 \pm 2.40$ & $---\cdot$ & --.- & $-\cdots$ \\
\hline \multicolumn{8}{|l|}{ Retroglossal space } \\
\hline Anteroposterior diameter, $\mathrm{cm}$ & $1.36 \pm 0.45$ & $1.40 \pm 0.45$ & 0.761 & $1.63 \pm 0.46$ & $1.53 \pm 0.70$ & 0.284 & 0.186 \\
\hline Lateral diameter, $\mathrm{cm}$ & $2.56 \pm 0.32$ & $2.53 \pm 0.94$ & 0.899 & $2.36 \pm 0.58$ & $2.15 \pm 0.41$ & 0.242 & 0.980 \\
\hline Area, $\mathrm{cm}^{2}$ & $2.47 \pm 0.97$ & $2.57 \pm 1.37$ & 0.776 & $2.52 \pm 0.91$ & $1.80 \pm 1.50$ & 0.099 & 0.183 \\
\hline Airway volume, $\mathrm{cm}^{3}$ & $3.83 \pm 1.78$ & $3.89 \pm 1.85$ & 0.623 & $3.80 \pm 1.78$ & $4.64 \pm 1.85$ & 0.147 & 0.485 \\
\hline
\end{tabular}

OSA: obstructive sleep apnea; and TP distance: tongue-pharyngeal distance (distance from the edge of the posterior third of the oral tongue to the posterior pharyngeal wall).*Waking state vs. sleep state. ${ }^{+}$Control group vs. OSA group.

sleep ( $p<0.001$ ), with a consequent increase in the mean volume of the lateral pharyngeal walls (from $15.8 \pm 6.3 \mathrm{~cm}^{3}$ to $\left.20.1 \pm 8.9 \mathrm{~cm}^{3} ; \mathrm{p}<0.001\right)$. In both groups, there was an inverse correlation between the increase in lateral pharyngeal wall volume and the reduction in the anteroposterior diameter of the retropalatal airway $(r=-0.54 ; p=0.019)$.
In the OSA group, there was posterior displacement of the tongue, as identified by a reduction in the tongue-pharyngeal distance from wakefulness to sleep (from $1.89 \pm 0.28 \mathrm{~cm}$ to $1.62 \pm 0.32 \mathrm{~cm}$; $\mathrm{p}=$ 0.001 ), as shown in Table 2 . In both groups, there was a direct correlation between the state-dependent change in the tongue-pharyngeal distance and that in 


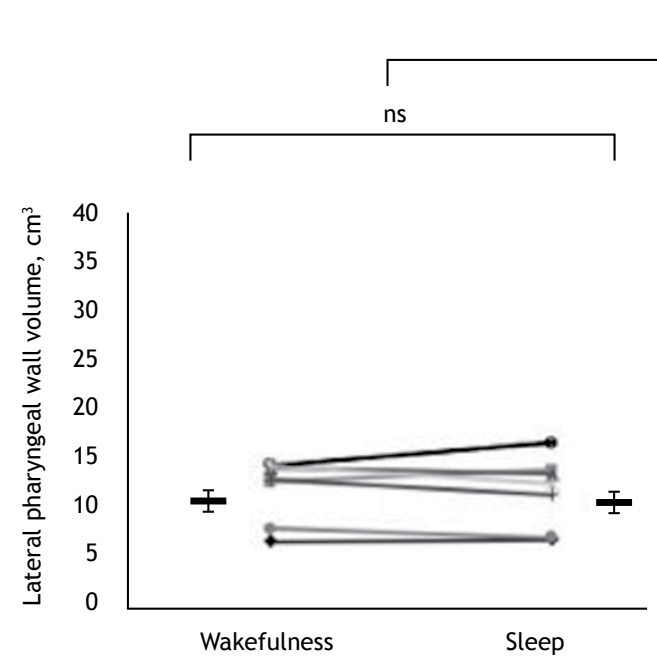

Healthy controls $p=0.01$

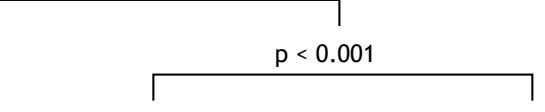

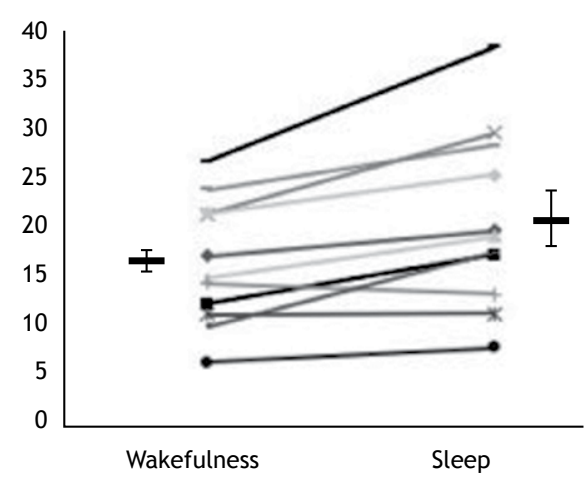

Patients with OSA

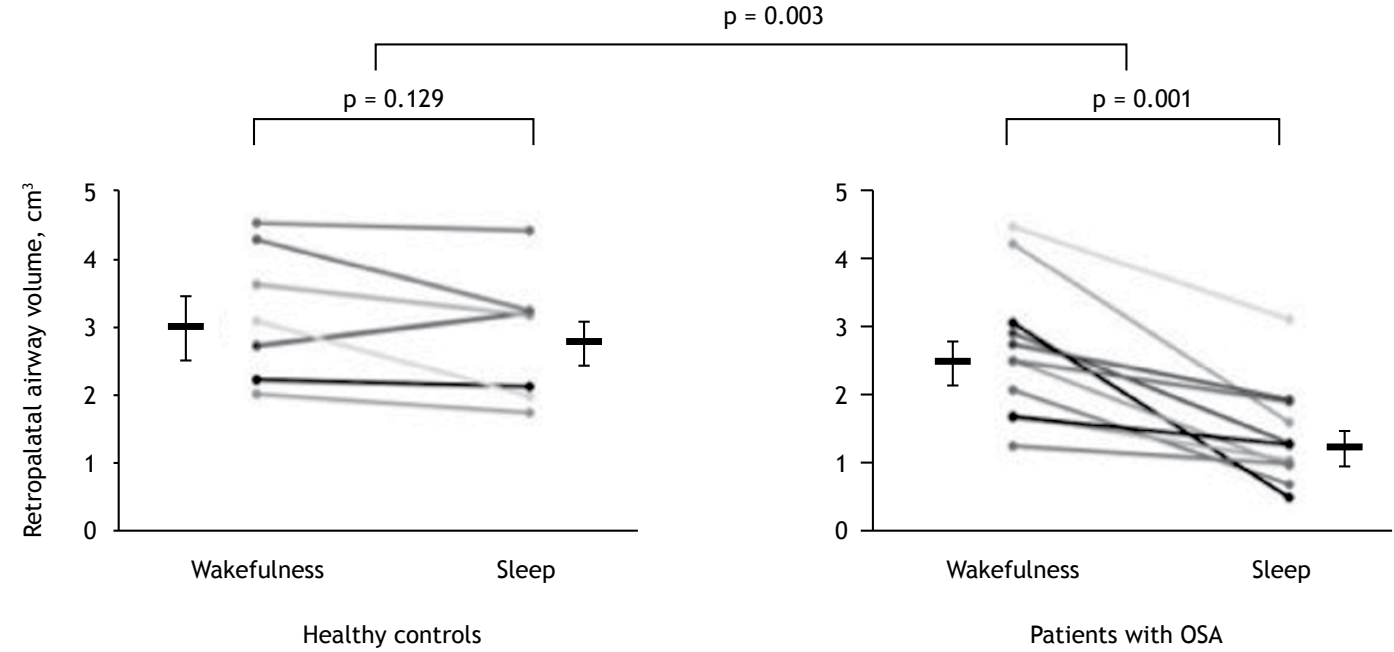

Figure 4. Individual changes in retropalatal upper airway volume and lateral pharyngeal wall volume (A and $B$, respectively) from the waking state to the sleep state among control and obstructive sleep apnea (OSA) group subjects. Short horizontal lines and bars indicate means and standard deviations, respectively. ns: not significant.

the anteroposterior diameter of the retropalatal airway ( $r=0.77 ; p<0.001)$, suggesting that the posterior displacement of the tongue during sleep is associated with anteroposterior narrowing of the retropalatal airway. Intraobserver agreement for lateral pharyngeal wall volume during wakefulness, determined from two measurements in each of 5 OSA group subjects, was high (intraclass correlation coefficient $=0.997$; $p<0.001)$.

\section{DISCUSSION}

Here, we have demonstrated that upper airway narrowing (from the waking state to the sleep state) occurs predominantly at the retropalatal level in patients with OSA and in healthy individuals. Among the OSA group subjects, the most important findings were the following: upper airway narrowing occurred at the retropalatal level; upper airway narrowing occurred in the lateral and anteroposterior dimensions of the retropalatal airway; narrowing of the lateral and anteroposterior dimensions of the retropalatal airway was due to an increase in the lateral pharyngeal wall volume and posterior displacement of the tongue, respectively. These findings are consistent with the concept that the pharynx is a complex and interdependent cylinder that can narrow as the result of dynamic changes in the lateral walls and tongue position from wakefulness to sleep.

Sleep studies employing DISE have shown that the upper airway typically collapses at the retropalatal level. (28-31) Although endoscopy provides direct visualization of the pharyngeal lumen, it does not provide any insights into the behavior of the 
surrounding structures. However, DISE has also shown retroglossal obstruction in some patients. One study demonstrated poor agreement between endoscopy and CT. ${ }^{(32)}$ Possible explanations would be the use of sedation in endoscopy (i.e., DISE) and the inability to evaluate the retropalatal and retroglossal airways simultaneously. Retroglossal collapse can be secondary to retropalatal failure, due to negative pharyngeal pressure. Another study showed that compliance is lower in the retroglossal region than in the retropalatal region. ${ }^{(33)}$ In this context, upper airway imaging studies, despite their demonstrable superiority, have not been widely used, because of major technical limitations. We were successful for several reasons. First, we used multidetector CT with 3D reconstructions. This technique allowed rapid ( $\leq 6 \mathrm{~s}$ ) acquisition with high resolution, thus minimizing artifacts. Second, in contrast to MRI, (18-21) CT scanning allowed sleep monitoring with standard full polysomnography. In a CT sleep study involving 4 subjects, Stein et al. ${ }^{(22)}$ showed that airway narrowing from the waking to the sleep state was greatest at the retropalatal level. Horner et al.(24) also used CT scans during wakefulness and sleep to evaluate 8 patients with OSA, demonstrating that the retropalatal region was the primary site of airway collapse. ${ }^{(19)}$ In a study comparing MRI and pharyngeal endoscopy during sedation in 24 patients with OSA and 9 patients with non-sleep-apnea snoring, Suto et al. ${ }^{(19)}$ found that both imaging methods showed changes occurring primarily at the retropalatal level. Barrera et al.(21) were able to obtain real-time MRI images in patients with OSA and controls. Although the authors also found that the retropalatal region was the most common site of obstruction, they did not assess the pattern of collapse or the behavior of the soft palate and lateral walls during upper airway obstruction. Trudo et al.(18) reported detailed upper airway dimensions during wakefulness and sleep; although they studied only subjects without OSA, they observed concomitant reductions in the anteroposterior and lateral dimensions of the retropalatal airway, which is in line with our observations. In contrast, Horner et al. ${ }^{(24)}$ showed that, among the 8 patients with OSA evaluated in their study, anteroposterior narrowing occurred in 6 , whereas lateral narrowing occurred in only 2 . In the present study, we found that the retropalatal region was the primary site of upper airway obstruction during sleep in patients with OSA and that such obstruction resulted from concomitant anteroposterior and lateral narrowing.

In the present study, imaging was performed during natural, well-documented sleep and showed that the reduction in upper airway volume occurred mainly at the retropalatal level in patients with OSA and in healthy controls. In contrast, the retroglossal region did not change significantly from the waking to the sleep state. These findings are in line with those of a previous study. ${ }^{(18)}$ In our OSA group subjects, anteroposterior narrowing of the retropalatal airway was associated with posterior displacement of the tongue and an increase in the lateral pharyngeal wall volume. The posterior third of the oral tongue lies in front of the soft palate, whereas the base of the tongue is in direct contact with the pharyngeal lumen. Due to its close proximity to the soft palate, the posterior third of the oral tongue can play an important role in retropalatal airway narrowing. ${ }^{(31)}$

Here, we have shown that the volume of the lateral pharyngeal walls increases during sleep in patients with OSA. A study evaluating only individuals without OSA showed an increase in the lateral pharyngeal wall thickness from wakefulness to sleep. ${ }^{(18)}$ Previous studies have demonstrated that continuous positive airway pressure (CPAP), ${ }^{(34)}$ mandibular advancement devices, ${ }^{(35)}$ and tongue stabilizing devices ${ }^{(14)}$ increase the lateral diameter of the retropalatal airway. The use of CPAP has also been shown to decrease lateral pharyngeal wall thickness. ${ }^{(34)}$ Because the base of the tongue is connected to the lateral walls of the soft palate via the palatoglossal arch, it has been suggested that airway splinting (with CPAP) and tongue protrusion (with mandibular advancement devices or tongue stabilizing devices) stretch those connections, thus increasing the lateral dimensions of the retropalatal airway. ${ }^{(36)}$ We speculate that the opposite occurs during sleep, when the posterior displacement of the tongue relaxes its connections with the retropalatal lateral walls, allowing folding of the lateral walls of the soft palate and a consequent increase in lateral pharyngeal wall volume. The position and configuration of the tongue, soft palate, and lateral pharyngeal walls are interdependent.

Our study has several potential limitations. First, we studied only men, and caution should therefore be used in extrapolating our results to women. Second, we employed $\mathrm{CT}$, which exposes subjects to radiation and does not allow continuous image acquisition. In addition, we chose to obtain images of the upper airway during obstructive respiratory events in patients with severe OSA. Therefore, the pattern of upper airway obstruction might be different in patients with milder forms of the disorder. Furthermore, image acquisition in our study was not respiratory-gated and might therefore have been subject to respiratory cycle variability. However, the expected variability within a single respiratory cycle is small. Moreover, the number of healthy (control) subjects was small and the control group subjects were not matched to the OSA group subjects for age and BMI. Therefore, the differences between the two groups might have been influenced by the BMI and age. Despite the limited power of the present study to detect differences in airway dimensions, our findings in normal subjects during sleep are similar to those of a previous study. ${ }^{(18)}$ Therefore, our control group provided confirmatory data. More importantly, our study was primarily designed to describe the dynamics of airway obstruction during obstructive respiratory events in patients with OSA.

In summary, our findings show that upper airway narrowing occurs predominantly at the retropalatal 
level among male patients with severe OSA and among healthy male controls. Patients with OSA present with upper airway obstruction resulting from narrowing of the lateral and anteroposterior dimensions of the retropalatal airway during sleep. Such obstruction occurs due to an increase in the lateral pharyngeal wall volume and posterior displacement of the tongue. These findings highlight the complex dynamic interactions that occur among pharyngeal soft tissue structures during airway obstruction.

\section{AUTHOR CONTRIBUTIONS}

Passos UL-conception of the work, data collection, drafting the article; Genta PR-data analysis and interpretation, critical revision of the article; Marcondes $\mathrm{BF}$-data collection, drafting the article; Lorenzi-Filho $\mathrm{G}$-critical revision of the article, final approval of the version to be published; Gebrim EMMS-conception of the work, critical revision of the article, final approval of the version to be published.

\section{REFERENCES}

1. Jordan AS, McSharry DG, Malhotra A. Adult obstructive sleep apnoea. Lancet. 2014;383(9918):736-47. https://doi.org/10.1016/ S0140-6736(13)60734-5

2. Tufik S, Santos-Silva R, Taddei JA, Bittencourt LR. Obstructive sleep apnea syndrome in the Sao Paulo Epidemiologic Sleep Study. Sleep Med. 2010;11(5):441-6. https://doi.org/10.1016/j.sleep.2009.10.005

3. Marin JM, Carrizo SJ, Vicente E, Agusti AG. Long-term cardiovascular outcomes in men with obstructive sleep apnoea-hypopnoea with or without treatment with continuous positive airway pressure: an observational study. Lancet. 2005;365(9464):1046-53. https://doi. org/10.1016/S0140-6736(05)71141-7

4. Mezzanotte WS, Tangel DJ, White DP. Influence of sleep onset on upper-airway muscle activity in apnea patients versus norma controls. Am J Respir Crit Care Med. 1996;153(6 Pt 1):1880-7. https://doi.org/10.1164/ajrccm.153.6.8665050

5. Nelson S, Hans M. Contribution of craniofacial risk factors in increasing apneic activity among obese and nonobese habitual snorers. Chest. 1997;111(1):154-62. https://doi.org/10.1378/chest.111.1.154

6. YuX, Fujimoto K, Urushibata K, Matsuzawa Y, Kubo K. Cephalometric analysis in obese and nonobese patients with obstructive sleep apnea syndrome. Chest. 2003;124(1):212-8. https://doi.org/10.1378/ chest.124.1.212

7. Davidson TM, Sedgh J, Tran D, Stepnowsky CJ. The anatomic basis for the acquisition of speech and obstructive sleep apnea: evidence from cephalometric analysis supports The Great Leap Forward hypothesis. Sleep Med. 2005;6(6):497-505. https://doi.org/10.1016/j. sleep.2005.03.007

8. Schorr F, Kayamori F, Hirata RP, Danzi-Soares NJ, Gebrim EM, Moriya HT, et al. Different Craniofacial Characteristics Predict Upper Airway Collapsibility in Japanese-Brazilian and White Men. Chest. 2016;149(3):737-46. https://doi.org/10.1378/chest.15-0638

9. Yucel A, Unlu M, Haktanir A, Acar M, Fidan F. Evaluation of the upper airway cross-sectional area changes in different degrees of severity of obstructive sleep apnea syndrome: cephalometric and dynamic C study. AJNR Am J Neuroradiol. 2005;26(10):2624-9.

10. Sutherland K, Lee RW, Phillips CL, Dungan G, Yee BJ, Magnussen JS, et al. Effect of weight loss on upper airway size and facial fat in men with obstructive sleep apnoea. Thorax. 2011;66(9):797-803. https://doi.org/10.1136/thx.2010.151613

11. Genta PR, Schorr F, Eckert DJ, Gebrim E, Kayamori F, Moriya HT et al. Upper airway collapsibility is associated with obesity and hyoid position. Sleep. 2014;37(10):1673-8. https://doi.org/10.5665/ sleep.4078

12. Jäger L, Günther E, Gauger J, Reiser M. Fluoroscopic MR of the pharynx in patients with obstructive sleep apnea. AJNR Am J Neuroradiol. 1998;19(7):1205-14.

13. Chi L, Comyn FL, Mitra N, Reilly MP, Wan F, Maislin G, et al. Identification of craniofacial risk factors for obstructive sleep apnoea using three-dimensional MRI. Eur Respir J. 2011;38(2):348-58. https://doi.org/10.1183/09031936.00119210

14. Sutherland K, Deane SA, Chan AS, Schwab RJ, Ng AT, Darendeliler MA et al. Comparative effects of two oral appliances on uppe airway structure in obstructive sleep apnea. Sleep. 2011;34(4):469 77. https://doi.org/10.1093/sleep/34.4.469

15. Schwab R, Pasirstein M, Pierson R, Mackley A, Hachadoorian R Arens $R$, et al. Identification of upper airway anatomic risk factors for obstructive sleep apnea with volumetric magnetic resonance imaging. Am J Respir Crit Care Med. 2003;168(5):522-30. https://doi. org/10.1164/rccm.200208-8660C

16. Schwab RJ, Gupta KB, Gefter WB, Metzger LJ, Hoffman EA, Pack
Al. Upper airway and soft tissue anatomy in normal subjects and patients with sleep-disordered breathing. Significance of the latera pharyngeal walls. Am J Respir Crit Care Med. 1995;152(5 Pt 1):167389. https://doi.org/10.1164/ajrccm.152.5.7582313

17. De Vito A, Carrasco Llatas M, Vanni A, Bosi M, Braghiroli A Campanini $A$, et al. European position paper on drug-induced sedation endoscopy (DISE). Sleep Breath. 2014;18(3):453-65. https:// doi.org/10.1007/s11325-014-0989-6

18. Trudo FJ, Gefter WB, Welch KC, Gupta KB, Maislin G, Schwab RJ. State-related changes in upper airway caliber and surrounding softtissue structures in normal subjects. Am J Respir Crit Care Med. 1998:158(4):1259-70. https://doi.org/10.1164/ajrccm.158.4.9712063

19. Suto Y, Matsuda E, Inoue Y, Suzuki T, Ohta Y. Sleep apnea syndrome: comparison of $\mathrm{MR}$ imaging of the oropharynx with physiologic indexes. Radiology. 1996;201(2):393-8. https://doi.org/10.1148/ radiology.201.2.8888230

20. Kavcic P, Koren A, Koritnik B, Fajdiga I, Groselj LD. Sleep magnetic resonance imaging with electroencephalogram in obstructive sleep apnea syndrome. Laryngoscope. 2015;125(6):1485-90. https://doi. org/10.1002/lary.25085

21. Barrera JE. Sleep magnetic resonance imaging: dynamic characteristics of the airway during sleep in obstructive sleep apnea syndrome. Laryngoscope. 2011;121(6):1327-35. https://doi. org/10.1002/lary.21810

22. Stein MG, Gamsu G, de Geer G, Golden JA, Crumley RL, Webb WR. Cine CT in obstructive sleep apnea. AJR Am J Roentgenol. 1987;148(6):1069-74. https://doi.org/10.2214/ajr.148.6.1069

23. Choi JK, Kee WC, Lee JM, Ye MK. Variable site of oropharyngeal narrowing and regional variations of oropharyngeal collapsibility among snoring patients during wakefulness and sleep. Cranio. 2001;19(4):252-9. https://doi.org/10.1080/08869634.2001.11746176

24. Horner RL, Shea SA, Mclvor J, Guz A. Pharyngeal size and shape during wakefulness and sleep in patients with obstructive sleep apnoea. Q J Med. 1989;72(268):719-35.

25. Drager LF, Bortolotto LA, Lorenzi MC, Figueiredo AC, Krieger EM Lorenzi-Filho G. Early signs of atherosclerosis in obstructive sleep apnea. Am J Respir Crit Care Med. 2005;172(5):613-8. https://doi. org/10.1164/rccm.200503-3400C

26. Iber C, Ancoli-Israel S, Chesson A, Quan SF. The AASM manual for the scoring of sleep and associated events, rules. Terminology and technical specifications. 1st ed. Westchester, IL: American Academy of Sleep Medicine; 2007

27. Cahali MB, Formigoni GG, Gebrim EM, Miziara ID. Latera pharyngoplasty versus uvulopalatopharyngoplasty: a clinical, polysomnographic and computed tomography measurement comparison. Sleep. 2004;27(5):942-50. https://doi.org/10.1093/ sleep/27.5.942

28. Vroegop AV, Vanderveken OM, Dieltiens M, Wouters K, Saldien V Braem MJ, et al. Sleep endoscopy with simulation bite for prediction of oral appliance treatment outcome. J Sleep Res. 2013:22(3):348 55. https://doi.org/10.1111/jsr.12008

29. Ravesloot MJ, de Vries N. One hundred consecutive patients undergoing drug-induced sleep endoscopy: results and evaluation. Laryngoscope. 2011;121(12):2710-6. https://doi.org/10.1002/ lary.22369

30. Kezirian EJ, Hohenhorst W, de Vries N. Drug-induced sleep endoscopy: the VOTE classification. Eur Arch Otorhinolaryngol. 2011;268(8):1233-1236. https://doi.org/10.1007/s00405-011-1633-8

31. Isono S, Tanaka A, Nishino T. Dynamic interaction between the tongue and soft palate during obstructive apnea in anesthetized 
patients with sleep-disordered breathing. J Appl Physiol (1985) 2003;95(6):2257-64. https://doi.org/10.1152/japplphysiol.00402.2003

32. Yan ZQ, Sun JJ, Chen X, Yuan W, Lin YS, Sun YM, et al. Comparative study of determining the sites of airway obstruction in obstructive sleep apnea hypopnea syndrome between real-time CT scans and laryngofiberscope technology [Article in Chinese]. Zhonghua Yi Xue Za Zhi. 2012;92(48):3389-92.

33. Marques M, Genta PR, Azarbarzin A, Sands SA, Taranto-Montemurro $\mathrm{L}$, Messineo $\mathrm{L}$, et al. Retropalatal and retroglossal airway compliance in patients with obstructive sleep apnea. Respir Physiol Neurobiol. 2018;258:98-103. https://doi.org/10.1016/..resp.2018.06.008
34. Schwab RJ, Pack Al, Gupta KB, Metzger LJ, Oh E, Getsy JE, et al. Upper airway and soft tissue structural changes induced by CPAP in normal subjects. Am J Respir Crit Care Med. 1996;154(4 Pt 1):110616. https://doi.org/10.1164/ajrccm.154.4.8887615

35. Chan AS, Sutherland K, Schwab RJ, Zeng B, Petocz P, Lee RW, et al. The effect of mandibular advancement on upper airway structure in obstructive sleep apnoea. Thorax. 2010;65(8):726-32. https://doi. org/10.1136/thx.2009.131094

36. Isono S, Tanaka A, Sho Y, Konno A, Nishino T. Advancement of the mandible improves velopharyngeal airway patency. J Appl Physiol (1985). 1995;79(6):2132-8. https://doi.org/10.1152/ jappl.1995.79.6.2132 